\title{
Numerical Simulation of Rainfall-runoff for Small-scale Basin
}

\author{
Tingyu Xu, Jianguo Xu, Jianjun Wang and Jinbai Huang * \\ School of Hydraulic, Energy and Power Engineering of Yangzhou University, Yangzhou, 225009, China \\ Jiangsu Surveying and Design Institute of Water Resources Co., Ltd., Yangzhou, 225127, China \\ Email: 798999802@qq.com \\ Email:xujianguojsss@sina.com \\ Email: wjj@yzu.edu.cn \\ Email: huangjinbai@hotmail.com \\ * Corresponding Author
}

\begin{abstract}
The distributed hydrological model of rainfallrunoff for the two small scale basins of the different topographic conditions were developed for the main objective to provide method reference for the further studies on distributed hydrological model of the small-scale basin. The Liudaogou Basin located at hilly-gully area of the northern Loess Plateau and Bukuro River Basin located at mountain area of the Tottori County of Japan were adopted as the studied locations. Modeling of soil vertical profile of the studied locations was conducted based on the field survey the numerical model for rainfall-runoff was developed based on the equations of kinematic wave theory combined with GIS-ArcMap; Applicability of the model was validated through numerical simulation of the observed runoff process. The results indicated that the simulation results exhibited relatively high precision, and the error was less than $3 \%$. A scientific method for surface runoff estimation was therefore provided for the studied locations.
\end{abstract}

Keywords- Basin; Topography; Distributed Hydrological Model; Rainfall-runoff; Numerical Simulation; Distributed Numerical Hydrological Model .

\section{INTRODUCTION}

The distributed hydrological model has the powerful simulation function because of its physical basis and distributed parameter in watersheds [1, 2], and has been rapidly developing in recent years [3]. The development of distributed hydrological model presents a trend towards different basin scales, multi-function and discipline, and the modular system $[4,5]$.

In China, the research on distributed hydrological model research for small-scale watershed has quickly developed in recent years. Zhang et al (2010) used BPCC (Basic Pollution Calculated Center) distributed hydrological model to research how climate fluctuation and the change of cover influence on runoff in Zhenjiang River Basin which is a tributary of Minjiang river[6]; Chen et al (2011) adopted Xitiaoxi watershed in the upper reaches of Taihu of Yangtze River Delta region as the study area and simulated rainfall runoff process with the distributed hydrological model of SWAT[7]; Yang et al(2013) carried out runoff simulation in Wo Hushan Reservoir watershed using SWAT[8]; Li et al (2013) applied physical basis distributed hydrological model
TOPKAPI combined with model of the Xin'An River in a flood simulation of Chen Village Basin[9]. The current research status on hydrological model in China represents that the most researches on distributed hydrological model of small watershed were mainly the case studies of using existing foreign models. Self-developed distributed hydrological model relying on the physical condition of the small watershed is relatively deficient. In this study, the two small-scale basins under different terrain conditions were chosen as the studied locations, the distributed rainfall-runoff model was developed based on GIS and basin topography and hydro-geological conditions, the results are expected to provide the method and technical references for further research on distributed hydrological model of the small-scale basin.

\section{MATERIALS AND METHODS}

\section{A. Field survey and observation}

The Liudaogou Basin is located at the hilly-gully region of Northern Loess Plateau $\left(110^{\circ} 21^{\prime} 110^{\circ} 23^{\prime} \mathrm{E}\right.$, $380^{\circ} 46^{\prime}-380^{\circ} 51^{\prime} \mathrm{N}$ ), and the Bukuro River Basin is located at the mountainous area in Tottori County in Japan $\left(134^{\circ} 12^{\prime}-134^{\circ} 26^{\prime} \mathrm{E}, \quad 35^{\circ} 25^{\prime}-35^{\circ} 29^{\prime} \mathrm{N}\right)$. The field hydrological observations and survey soil vertical profile condition were conducted in each studied location. The surface runoff observation was conducted at the upstream of the Liudaogou Basin (catchment area: $0.1 \mathrm{~km}^{2}$ ). The catchment of the surface runoff observation area was 31.8 $\mathrm{km}^{2}$ in Bukuro River Basin.

\section{B. Model development}

\section{1) Modeling soil vertical profile}

Modeling of soil vertical profile, by which carry water movement after the rainwater fall to the ground, is essential for numerical calculation in the vertical direction. On this model of the vertical soil profile, water movement is constrained by the actual physical condition of underlying topography. Model lumping of the Liudaogou Basin and the Bukuro River Basin (Fig. 2, Fig. 3) which involves the thickness of soil layers and groundwater (phreatic water) distribution was developed based on the results of actual multi-point survey on soil vertical profile mainly with method of drilling small bore wells. The 
model was conventionally composed of slope and river channel. The slope sector was separated into two soil layers in the vertical profile from ground surface to rock stratum. At the river channel, modeling of vertical profile from river bed to the surface of confined groundwater was considered as only one layer in the Liudaogou Basin (Fig. 1), and the river channel sector was considered as composition of two Layers in the Buroku River Basin (Fig. 2). Water budget and each component of water inflow and outflow in model profile were schematically depicted in Fig. 1 and Fig. 2.

Rainfall

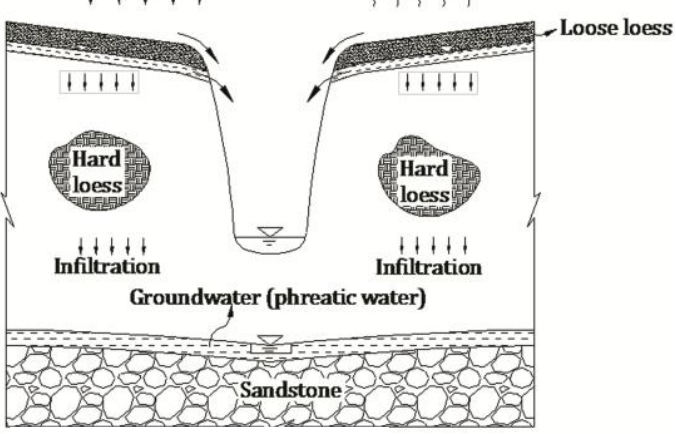

(a) The vertical soil profile model of Liudaogou Basin.

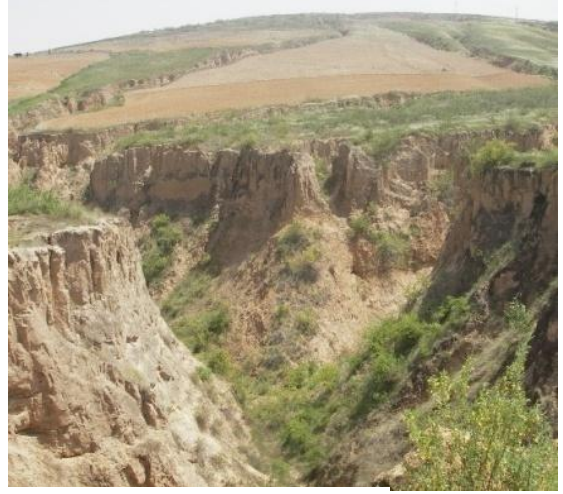

(b) The typical gully terrain portrait of Liudaogou Basin

Figure 1. Modeling of soil vertical profile of Liudaogou Basin and topographic photo (partial view)

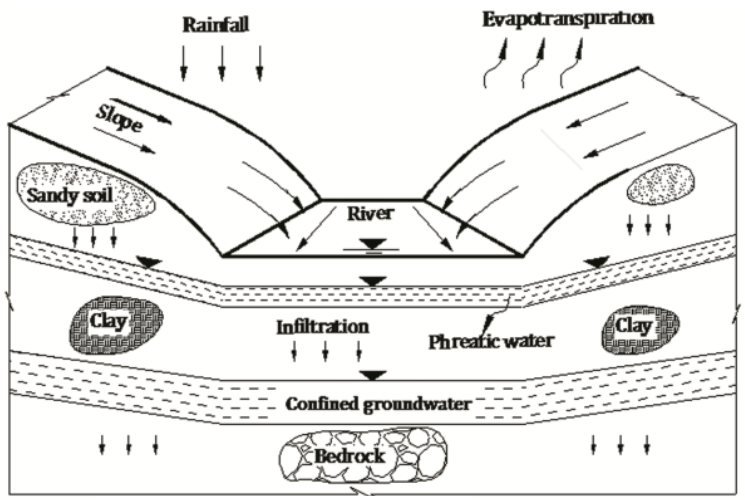

(a) The vertical soil profile model of Bukuro Basin.

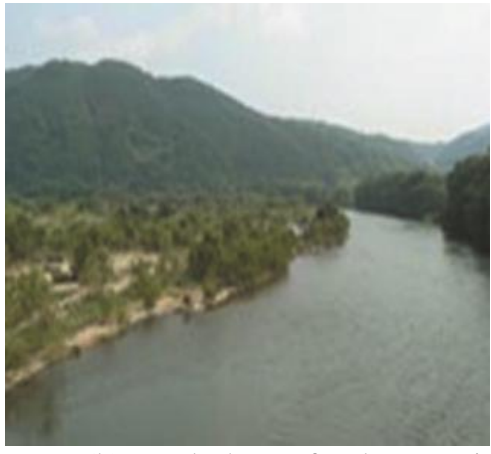

(b) Local photo of Bukuro Basin

Figure 2. Modeling of soil vertical profile of Bukuro Basin and topographic photo (partial view)

\section{2) DEM and River channel networks}

DEM (digital elevation model) and river channel network of each studied location was generated by GISArcMap. Grid size of DEM must fit basin area for that topographical feature can be depicted clearly. Grid size of DEM for runoff calculation area $\left(0.1 \mathrm{~km}^{2}\right)$ of Liudaogou Basin was adopted as $5 \mathrm{~m} \times 5 \mathrm{~m}$ so that high-density gully was visibly represented. Grid size of the Bukuro River Basin was adopted as $50 \mathrm{~m} \times 50 \mathrm{~m}$. Sub-basin delineation was carried out based on spatial connection of each tributary on river channel network and the distributed basin model of each studied location was achieved as shown in Fig. 3 and Fig. 4, respectively.

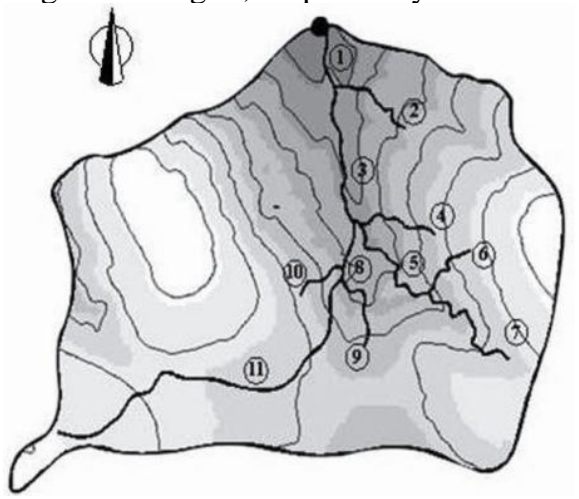

(a)River channel network of the study area in the Liudaogou Basin

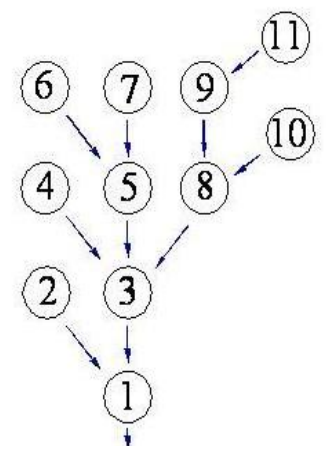

(b) The relationship of spatial connection of ach small basin.

Figure 3. River channel network of the study area of the Liudaogou Basin and spatial connection of each small Basin 


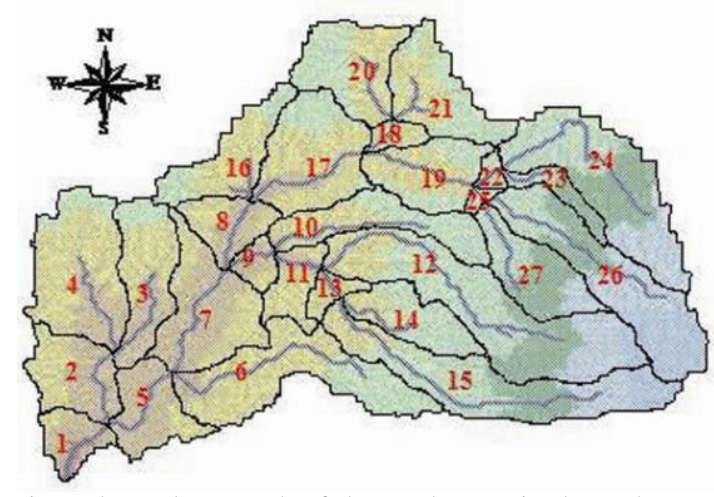

(a)River channel network of the study area in the Bukuro River Basin

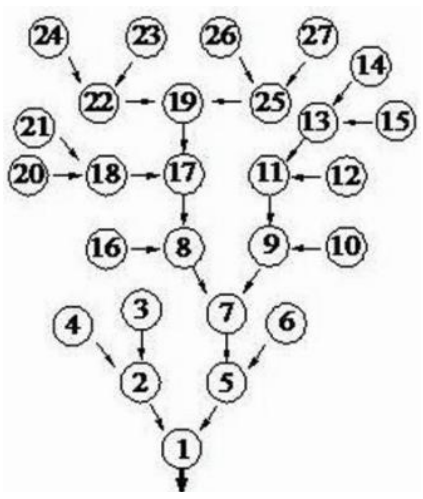

(b) The relationship of spatial connection $f$ each small basin.

Figure 4. River channel network of the study area of the Bukoro River Basin and spatial connection of each small Basin

\section{3) Basic equations}

To evaluate the water flow in the basin, a numerical method using the kinematic wave theory was used. The kinematic wave model has been used widely in rainfallrunoff modeling $[10,11]$. It is a physically-based model as it uses physical parameters to characterize a basin. The kinematic model has been also applied to describe the features of infiltration and subsurface lateral flows [12].

The surface runoff continuity equation (for slope)

$$
\frac{\partial h}{\partial t}+\frac{\partial q}{\partial x}=r-f_{1}
$$

Manning's average velocity formula:

$$
v=\frac{1}{n} R(h)^{\frac{2}{3}} I^{\frac{1}{2}}
$$

$$
Q=v A(h)
$$

Where, $\mathrm{d} t$ : unit time $(\mathrm{s}) ; \mathrm{d} x$ : unit distance in flow direction, $(\mathrm{m}) ; h$ : depth of water, $(\mathrm{m}) ; q$ : discharge of unit width $\left(\mathrm{m}^{2} / \mathrm{s}\right) ; r$ : effective rainfall, $(\mathrm{m} / \mathrm{s}) ; f_{l}$ : mean infiltration velocity of the $1^{\text {st }}$ soil layer $(\mathrm{m} / \mathrm{s}) ; n$ : coefficient of the roughness $\left(\mathrm{s} \cdot \mathrm{m}^{-1 / 3}\right) ; R$ : hydraulic radius, $(\mathrm{m}) ; I$ : gradient of the slope; Q: flow discharge, $\left(\mathrm{m}^{3} / \mathrm{s}\right) ; v$ : flow velocity, $(\mathrm{m} / \mathrm{s})$; $A$ : sectionalarea of flow, $\left(\mathrm{m}^{2}\right)$.
Basic equations for infiltration flow (groundwater) calculation are follows.

Equation of continuity (for the first soil layer) for slope sector:

$$
\lambda \frac{\partial \bar{h}}{\partial t}+\frac{\partial \bar{q}}{\partial x}=f_{1}-f_{2}-E T
$$

Darcy's law

$$
\bar{q}=k \bar{I} \bar{h}
$$

Where, $\lambda$ : effective porosity; $\bar{h}$ : Depth of the groundwater flow, $(\mathrm{m}) ; \bar{q}$ : discharge of the unit width, $\left(\mathrm{m}^{2} / \mathrm{s}\right) ; E T$ : evapotranspiration, $(\mathrm{m} / \mathrm{s}) ; k$ : coefficient of permeability, $(\mathrm{m} / \mathrm{s}) ; f_{2}$ : mean infiltration velocity of the $2^{\text {nd }}$ soil layer, $(\mathrm{m} / \mathrm{s}) ; \bar{I}$ : gradient of the groundwater table.

The equations for calculation in the subsequent soil layer were analogous with those of the first soil layer. There are only some minor differences in the footnote number and the sectional form. The equations for the river channel are similar to those for the slope. Only some factors in the equations were replaced, which resulted in variation of the equations in forms.

\section{4) Initial and boundary conditions}

As the initial condition, discharges of the surface flow were assumed as 0 at the end of the upstream (the origin of the flow) at each distributed basin of the last stage (Fig. 3, Fig. 4). Initial (boundary) groundwater depth of calculation start time was determined by the actual survey.

In the process of the calculation, the vertical boundary conditions were given by the relationship between the depth of water and the infiltration velocity. For example, the actual infiltration from the surface into the first soil layer is equal to the depth of water $\left(h_{\mathrm{i}}\right)$ divided by the unit of time $(\mathrm{d} t)\left(\alpha=h_{\mathrm{i}} / \mathrm{d} t\right)$ when $h_{\mathrm{i}} / \mathrm{d} t<f_{1}$, the actual infiltration velocity from surface flow to the first layer was $h_{\mathrm{i}} / \mathrm{d} t\left(\operatorname{not} f_{1}\right)$.

\section{5) Parameter calibration}

Model parameters were given by field survey, experiment and used digital elevation model (DEM: Fig. 3, Fig.4) of each studied location. For example, the gradient of slopes and river channel were obtained by DEM combined with land-leveling survey. The thickness of soil layer was given by field measurement combined with referencing actual conditions of the existing phreatic water wells. Some parameters related to the soil hydraulic properties such as infiltration velocity, soil porosity were determined by infiltration experiment. Value of each parameter represents spatiotemporal change due to inconsistency of the underlying layer.

Evapotranspiration is essential to be considered as a factor influencing on runoff during the period of calculation. The main vegetation of the calculation area in the Liudaogou Basin is grassland (natural meadow). Evapotranspiration over grassland was calculated by using the Penman-Monteith equation (as (6)) [13], which have already been proven to be a suitable method in calculating the evapotranspiration at the Liudaogou Basin [14]. 


$$
l E T=\frac{\Delta\left(R_{n}-G\right)+c_{p} \rho \frac{\left(e_{s}-e_{a}\right)}{r_{a}}}{\Delta+\gamma\left(1+\frac{r_{s}}{r_{a}}\right)}
$$

Where, lET : latent heat flux in the soil, $\left(\mathrm{MJ} \cdot \mathrm{m}^{-2} \cdot \mathrm{h}^{-1}\right) ; l$ : latent heat of vaporization, $\left(\mathrm{MJ}^{\mathrm{kg}}{ }^{-1}\right) ; \quad E T$ : evapotrans piration, $\left(\mathrm{mm} \cdot \mathrm{h}^{-1}\right) ; \Delta$ : the slope of the saturation vapor-pressure at air temperature, $\left(\mathrm{kPa}^{\circ} \mathrm{C}^{-1}\right) ; \gamma$ : the psychometric constant, $\left(\mathrm{kPa} \cdot{ }^{\circ} \mathrm{C}^{-1}\right) ; e_{s}$ : saturated vaporpressure at air temperature, $(\mathrm{kPa}) ; e_{a}$ : actual vapor-pressure $(\mathrm{kPa}) ; R_{n}$ : net radiation, $\left(\mathrm{MJ} \cdot \mathrm{m}^{-2} \cdot \mathrm{h}^{-1}\right) ; G$ : soil heat flux, $\left(\mathrm{MJ} \cdot \mathrm{m}^{-2} \cdot \mathrm{h}^{-1}\right) ; c_{p}$ s pecific heat of air, $\left(1.0 \times 10^{-3} \mathrm{MJ} \mathrm{kg}^{-1} \cdot{ }^{\circ} \mathrm{C}^{-1}\right)$; $\rho$ :air density at constant pressure, $\left(\mathrm{kg} \cdot \mathrm{m}^{-3}\right) ; r_{a}$ : aerodynamic resistance, $\left(\mathrm{s} \cdot \mathrm{m}^{-1}\right) ; r_{s}$ : the surface res istance, $\left(\mathrm{s} \cdot \mathrm{m}^{-1}\right)$.

Seasonal vegetation evidently changed in the Bukuro River Basin so it is difficult to estimate evapotranspiration accurately due to frequent change of vegetation cover or its inconsistent distribution even if during the vegetation period. A loss coefficient was adopted to approximately evaluate evapotranspiration in the process of rainfallrunoff calculation for the Bukuro River Basin.

Conventionally, it is difficult to get the determination of some parameters directly by way of field survey, experiment, and using DEM such as infiltration velocity and soil porosity of the second soil layer of the slope, the loss coefficient used for assessing evapotranspiration, and etc. The process for calibrating such parameters is as follows: at first, each undetermined parameter was assigned a relatively rational initial value; next, massive model calculation had been carried out and comparis on of the observed flow discharge and the calculated value was performed and errors were filtered; at last, the parameters, by which the smallest error was produced, were chosen for numerical calculation [15]. A large number of parameters were used in rainfall-runoff calculation for the two studied locations and the corresponding content was omitted here.

\section{RESULTS AND DISCUSSION}

Numerical model was developed by computer language of FORTRAN to achieve combination of rainfall-runoff process with river channel network and soil vertical profile model of each studied location (the process for model development was omitted). Model validation was validated through simulation of the observed runoff process combined with correlation test and error analysis .

The simulation results of calculated results and observed one for rainfall-runoff of each studied location were represented in Fig. 5 and Fig. 6, respectively. The calculation results reproduced the observed results well, and the numerical results showed excellent fit with the observed data which indicated numerical model was applicable for rainfall-runoff calculation for the three studied locations.

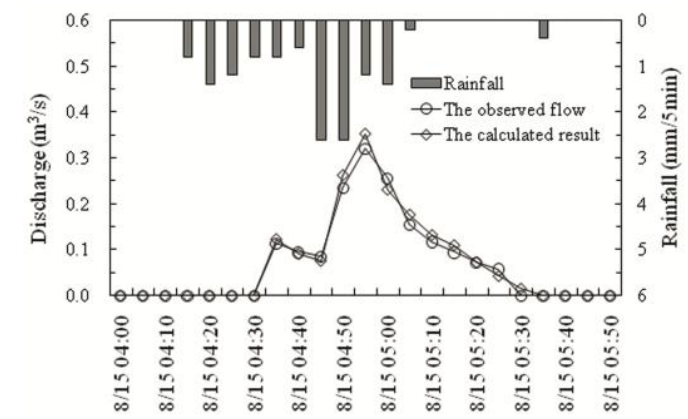

(a) 15 Aug 2005

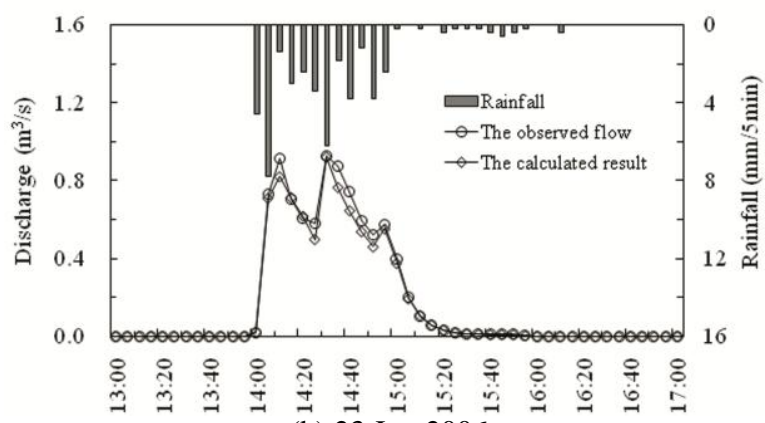

(b) 23 Jun 2006

Figure 5. The simulation result s of rainfall-run off events for Liudaogou Basin

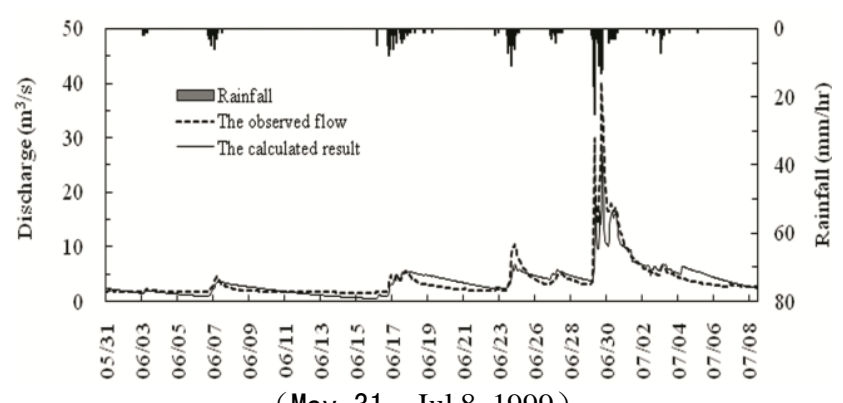

(May 31-Jul 8, 1999)

Figure 6. The simulation result of rainfall-runoff for Bukuro Basin (31 May-8 Jul, 1999)

Equation (7) recommended by Japan River erosion control technical criterion of MLIT (1997) was adopted as criterion function for error analysis [16]. The allowable error by this criterion is 0.03 .

$$
E=\frac{1}{n} \sum_{i=1}^{n}\left\{\frac{Q_{o}(i)-Q_{c}(i)}{Q_{o p}}\right\}^{2}
$$

Where $E$ : error; $n$ : number of calculation; $Q_{\mathrm{o}}(\mathrm{i})$ : observed discharge at moment $i,\left(\mathrm{~m}^{3} \cdot \mathrm{s}^{-1}\right) ; Q_{\mathrm{c}}(\mathrm{i})$ : calculated discharge at moment $i,\left(\mathrm{~m}^{3} \cdot \mathrm{s}^{-1}\right) ; Q_{\mathrm{op}}$ : the maximum discharge of the observed flow during the calculated time, $\left(\mathrm{m}^{3} \cdot \mathrm{s}^{-1}\right)$.

Error calculation was firstly performed for the simulation results as shown in Fig. 5 and Fig. 6, the error results were all less than 0.03. Error calculation was randomly carried out for the simulation results in other period (besides the calculated time as shown in Fig. 5 to Fig. 6). The results of error analysis represented that the error was less than the criterion allowable value. The analys is of the simulation results represents that the model 
is applicable for the rainfall-runoff calculation in the two studied locations.

\section{CONCLUSIONS}

A distributed numerical hydrological model was developed for rainfall-runoff calculations for the Liudaogou Basin and the Bukuro River Basin, respectively, based on the actual geological conditions of the studied locations using kinematic wave equations combined with GIS-ArcMAP; the model validity was validated through numerical simulation of the observed runoff, and the error was less than 0.03 ; a practical method for estimating surface runoff was therefore provided for the Liudaogou Basin and the Bukuro River Basin.

\section{ACKNOWLEDGMENT}

The authors gratefully acknowledge the financial support from the National Natural Science Foundation of China (NSFC) (No. 41271046), a project funded by the Priority Academic Program Development of Jiangsu Higher Education Institutions (PAPD), and Academic and Scientific Innovation Fund of undergraduate of Yangzhou University (No.X2014456).

\section{REFERENCES}

[1] R. S. Chen, E. S. Kang, J. P. Yang, and J. S. Zhang, "Research review of hydrological modeling", Journal of Desert Research, 2003, vol. 23 (3), pp. 221-228. (in Chinese with English abstract)

[2] X. Jin, Z. C. Hao, and J. L. Zhang, "Research evolution and development direction of hydrological models", Research of Soil and Water Conservation, 2006, vol. 23(3), pp. 197-199. (in Chinese with English abstract)

[3] H. F. Yang, X.. H. Wang, and P. Wen, "Overview of studies on distributed hydrological model", Water Resources and Power, 2008, vol. 26(6), pp. 1-4. (in Chinese with English abstract)

[4] M. K. Jain, U. C. Kothyari, and R. K. G. Ranga, "A GIS based distributed rainfall-runoff model", Journal of Hydrology, 2004, vol. 299 (1-2), pp. 107-135.

[5] T. Karvonena, H. Koivusaloa, and M. Jauhiainena, "A hydrological model for predict ing run off from different land use areas",. Journal of Hydrology, 1999, vol. 217 (3-4), pp. 253-265.
[6] H. L. Zhang, D. X. Li, and X. K. Wang, "BPCC model based runoff responses to climate fluctuation and land cover changes", Journal of T singhua University (Sci \& Tech), 2010, vol. 50(3), pp. 376-379. (in Chinese with English abstract)

[7] Y. Chen, Y. P. Xu, and X. W. Chen, "Hydrologic response to fut ure urbanization in small or medium basins in the Yangtze River Delta region”, Resources Science, 2011, vol. 33(1), pp. 64-69. (in Chinese with English abstract)

[8] S. S. Yang, Z. H. Xu, K. Kong, S. J. Miao, and S. D. Zhang, "A flow simulation based on SWAT model in Wohushan Reservoir Basin”, Journal of China's rural hydropower, 2013, vol. 5, pp. 1114, 19. (in Chinese with English abstract)

[9] Z. J. Li, X. Q. Wang, Y. X. Lv, L. Z. Chen, and L. R. Li, "Application of TOPKAPI model and comparison with Xin'anjiang model", Water Power, 2013, vol. 39(11), pp. 6-10. (in Chinese with English abstract)

[10] A. Yomoto, and M. N. Islam, "Kinematic analysis of flood runoff for a small-scale upland field", Journal of Hydrology, 1992, vol. 137(1-4), pp. 311-326.

[11] L. H. C. Chua, T. S. W. Wong, and L. K. Sriramula, "Comparison between kinematic wave and artificial neural network models in event based runoff simulation for an overland plane", Journal of Hydrology, 2008, vol. 357(3-4), pp.337-348.

[12] M. C. Cabral, L. Garrote, R. L. Bras, and E. Dara, "A kinematic model of infiltration and runoff generation in layered and sloped soils", Advances in Water Resources, 1992, vol. 15(5), pp. 311324.

[13] R. G. Allen, L. S. Pereira, D. Raes, and M. Smith, "Crop evapotranspiration: Guidelines for computing crop water requirements", FAO Irrigation and Drainage Paper 56, Food and Agriculture Organization of the United Nations (FAO), Rome, 1998.

[14] R. Kimura, J. Fan, X. C. Zhang, N. Takayama, M. Kamichika, and N. Matsuoka, "Evapotranspiration over the grassland field in the Liudaogou basin of the Loess Plateau, China", Acta Oecologica, 2005, vol. 29(1), pp. 45-53.

[15] J. B. Huang, O. Hinokidani, H. Yasuda, and Y. Kajikawa, "Study on characteristics of the surface flow of the upstream region of Loess Plateau", Annual Journal of Hydraulic Engineering, JSCE, 2008, vol. 52, pp. 1-6.

[16] Japanese River Society, "River erosion control technical criterion of MLIT (Ministry of Land, Infrastructure, Transport and Tourism)", Sankaido, Tokyo, 1997, pp. 85-87. 